\title{
Modeling Economy-wide vs Sectoral Climate Policies Using Combined Aggregate-Sectoral Models
}

\author{
William Pizer, Dallas Burtraw, Winston Harrington, \\ Richard Newell, and James Sanchirico*
}

\begin{abstract}
Economic analyses of climate change policies frequently focus on reductions of energy-related carbon dioxide emissions via market-based, economy-wide policies. The current course of environment and energy policy debate in the United States, however, suggests an alternative outcome: sectorbased and/or inefficiently designed policies. This paper uses a collection of specialized, sector-based models in conjunction with a computable general equilibrium model of the economy to examine and compare these policies at an aggregate level. We examine the relative cost of different policies designed to achieve the same quantity of emission reductions. We find that excluding a limited number of sectors from an economy-wide policy does not significantly raise costs. Focusing policy solely on the electricity and transportation sectors doubles costs, however, and using non-market policies can raise cost by a factor of ten. These results are driven in part by, and are sensitive to, our modeling of pre-existing tax distortions.
\end{abstract}

\section{INTRODUCTION}

Achieving environmental goals at lowest cost has sparked considerable interest in flexible, market-based policies that typically limit pollution by requiring emission sources to obtain a permit for each unit of pollution released. An overall emission cap is established by distributing a fixed number of these permits

The Energy Journal, Vol. 27, No. 3. Copyright @2006 by the IAEE. All rights reserved.

* Pizer, Burtraw, Harrington, Newell and Sanchirico are Senior Fellows at Resources for the Future. The authors appreciate outstanding assistance from Ranjit Bharvirkar, Matt Cannon, Kenny Gillingham, Martin Heintzelman, David Lankton, Meghan McGuinness, and Anthony Paul. We acknowledge financial support from U.S. Department of Energy grant DE-FG02-98ER62702. We also appreciate comments on earlier drafts from John Houghton and Michael Toman, seminar participants at George Washington University, Harvard University, and Centre International de Recherche sur Environnement et le Développement, as well as from four referees. All errors and opinions remain the responsibility of the authors. Address correspondence to William Pizer, Resources for the Future, 1616 P Street NW, Washington DC 20036 (email: pizer@rff.org). 
and flexibility is introduced by allowing users to freely trade the permits in a market. Market-based policies are also currently being used to address water pollution (Boyd et al. 2003), lead in gasoline (Stavins 2002), and overfishing (Newell et al. 2005).

Opposition to these policies can arise because in the process of creating a permit market, substantial transfers of wealth are possible-transfers that would not occur under non-market-based alternatives. For instance, users who previously paid nothing to emit pollution may now face the prospect of buying permits from a competitor or a regulatory agency. Furthermore, people and firms who are not directly regulated may see a greater increase in the price of pollution-intensive goods compared to command-and-control policies because every unit of emission incurs an opportunity cost. ${ }^{1}$ Related to this concern is the fact that market-based policies to address climate change would operate primarily by raising the cost of using fossil fuels; meanwhile broad support remains for low energy prices as a means to promote economic growth (National Energy Policy Development Group 2001).

Traditionally only certain sectors have been the target of environmental regulation on emissions; namely, transportation, electricity generation, and heavy industry. As attention shifts to carbon dioxide, however, the logic behind excluding agriculture, small businesses, and household is not so clear. The "old" reasoning goes that direct emissions from these sources are small and diffuse, expensive to control, or difficult to regulate. With carbon dioxide emissions, however, these small sources are in principle easy to regulate because emissions can be computed based on the volume of purchased fuels. While direct emissions from these sectors remain a relatively small fraction of total emissions, they may still offer a disproportionate volume of inexpensive mitigation opportunities.

Given the noted opposition to market-based policies and the traditional focus of environmental policy on some sectors, it is not surprising that most existing or proposed policy measures to reduce fossil fuel use and mitigate climate change have been sector-based, regional, and/or non-market policies. During the $107^{\text {th }}$ Congress, two bills were introduced that would have established a cap-andtrade program for carbon dioxide emissions only from power plants. Several bills were also introduced that focused on tighter fuel economy standards for automobiles. The President's National Energy Policy proposed new efficiency standards and renewable energy subsidies. Only the McCain-Lieberman bill (S.139) introduced in the $108^{\text {th }}$ Congress, and more recently the Bingaman amendment to the Energy Bill (SA. 868) introduced in the $109^{\text {th }}$, proposed something approaching an economy-wide architecture.

Absent concrete federal action, state-level policies have also forged ahead. California has enacted new motor vehicle efficiency requirements (State

1. Under some designs that involve output-based allocation of emission allowances or refund of emission fees within the regulated sector, product prices could actually decline compared to the absence of regulation. This is because the allocation of permits or revenues based on output constitutes an output subsidy that reduces variable costs of production and introduces inefficiencies in product pricing (Burtraw et al. 2001; Fischer 2001). 
of California 2004), nine northeastern states are negotiating a regional emission cap for power plants (RGGI State Commissioners 2003), and 17 states have a renewable portfolio standard (RPS), which target a specific portion of renewable generation as part of the electricity generation mix (Union of Concerned Scientists 2004).

With the divergence of most proposed policies from what is argued to be a more cost-effective economy-wide approach, an important policy question is just how much more expensive are sector-based, regional and/or non-market policies likely to be $?^{2}$ One recent study used a rule of thumb approach to analyze state-level policies and concluded they would be ten times more expensive than federal policy (Bast et al. 2003). Even as this question becomes increasingly important, most of the economic modeling has focused on economy-wide, market-based approaches (EIA 1998; Weyant and Hill 1999). This partly reflects the absence of suitable sectoral detail in many models, and partly the inherent difficulties in modeling non-market policies. It may also reflect optimism that an economy-wide approach may yet prevail.

Our paper departs from the existing economic studies in a number of important ways and examines the likely difference in costs among prominent combinations of sectoral carbon-price and non-price policies. First, we make use of detailed studies of sectoral behavior to understand and model the likely response of the electric power, household transportation, and industrial sectors to several different policies to reduce carbon dioxide emissions. In addition to the standard market-based "carbon price" policies of tradable permits or carbon taxes, we consider the possibility of a RPS in the power sector (minimum requirements for the share of renewable energy), fuel economy standards in the transportation sector, and uniform percentage reduction targets in the industrial sector. Second, we use these modeled responses to parameterize simpler representations of each sector. These representations - of responses to both market and non-market policiesare then combined in an economy-wide computable general equilibrium (CGE) model. The CGE model allows us to consider effects outside the regulated market, interactions with other distortions and trade effects in the economy, as well as interactions with other carbon price and non-price policies in different sectors.

Using these models we make several observations that hold over a range of reductions up to ten percent. Our benchmark is an auctioned permit system covering all emissions with auction revenues used to cut income taxes. First, the exclusion of certain sectors-such as residential, construction, commercial, and

2. Parry and Williams (1999) show that an economy-wide approach is not guaranteed to be more efficient when interactions with preexisting distortions in the economy are taken into account. This result applies to a vector of carbon reductions supplied from different sectors. Diamond and Mirrlees (1971) show that under optimal taxes, vectors of public good production can be valued at producer prices. This implies that an economywide policy is optimal, equating the marginal (producer) cost of abatement across sectors. In the absence of optimal taxes, however, the result is ambiguous because public goods such as $\mathrm{CO}_{2}$ abatement cannot be valued at producer prices. Therefore, equating producer costs of abatement across sectors no longer guarantees optimality and welfare maximization may involve higher producer costs in some sectors. 
government direct use of fossil fuels-does not noticeably affect the cost of an otherwise economy-wide tradable permit system (including electricity production, industry, and transportation). Second, and in contrast to the first observation, a market-based policy covering just electricity and household transportation (and excluding industry and commercial transportation) has costs about twice as high for a given volume of emission reductions as an economy-wide approach. Finally, a national renewable portfolio standard coupled with tighter corporate average fuel economy (CAFE) standards for automobiles is more than ten times as expensive. The increase in cost is split almost evenly between the two policies, which are designed to achieve the same fractional reduction in each sector. While economic theory tells us that a flexible, economy-wide program to reduce emissions is not necessarily least cost in an economy with existing distortions, in our simulation model we estimate that it does in fact do noticeably better than at least two competing alternatives (see footnote 2).

There is one important caveat to our findings. The comparison we make is between an emissions tax with revenue recycled in an efficient manner to sector policies that target emissions only indirectly. We do not, however, compare the sector policies to a less efficient emissions tax or trading program in which revenues are not recycled efficiently, for example, if permits are grandfathered to incumbent emitters. This is an extension we leave for future work.

Nonetheless, we feel our observations support a number of conclusions. Efforts to include all sources of carbon dioxide emissions-beyond electricity, transportation, and industry - in a flexible, economy-wide mitigation program may not deliver noticeably lower costs. However, the use of $\mathrm{CO}_{2}$ emissions trading, rather than an RPS or CAFE, would appear to offer significant cost savings. In the case of an RPS, the inefficiency arises because an RPS does nothing to encourage substitution from coal to gas for electricity generation since it does not put a price directly on emissions. In the case of CAFE, the higher costs owe in part to our representation of pre-existing tax distortions, namely the presence of taxes on the returns to capital invested in production by firms but the absence of taxes on returns to capital invested in "household production," in particular, personal transportation. These conclusions follow, in part, from our unique use of both sectoral and aggregate CGE modeling.

The next section summarizes the model structure of the detailed electricity, household transportation, and industrial sector models we employed, and describes the application of alternative climate policies to those sectors. Following this, we describe how we used the detailed sectoral results to represent these sectors in an aggregate CGE model, how we modeled non-price policies within the CGE framework, and additional CGE modeling details. We then discuss the CGE model results, compare the partial and general equilibrium results, and offer concluding comments. 


\section{MODELING SECTOR-SPECIFIC POLICIES}

Energy use can be difficult to model, as it is often associated with the use of long-lived capital, ranging from automobiles with a 15-year life, to buildings with a 50-year life, to electricity generating assets with potentially an even longer life. In addition, energy markets have often been regulated, ranging from electric utility regulation by public commissions to efficiency standards for building construction, home appliances, and automobile performance. In part, this regulation represents a response to various market failures that exist surrounding energy use, including natural monopolies and incomplete information. In support of and in response to policy development and evaluation, many modeling approaches have been developed by the private, government, and academic sectors to study the idiosyncrasies of energy use in particular sectors.

Our effort has taken advantage of several existing lines of this work. For example, the Energy Information Administration's (EIA) National Energy Modeling System (NEMS) has been developed over many years for the purpose of forecasting energy prices and use at both an aggregate and disaggregated level, resulting in publications such as the Annual Energy Outlook. In addition, NEMS has been employed to analyze the costs and emission consequences of several proposed environmental initiatives, including the Kyoto Protocol (EIA 1998), multipollutant legislation (EIA 2000), and the recent McCain-Lieberman proposal (EIA 2003). As described further below, our electricity and industrial sector models build, to various degrees, on sectoral sub-models within NEMS. Our electricity model also takes advantage of efforts using the Integrated Planning Model (IPM) for the power sector (e.g., US EPA 1998). In the transportation sector we use a stock/flow model of the vehicle fleet similar to that developed by Berkovec (1985), informed by a discrete-continuous econometric model of vehicle ownership and use (Train 1986). More detailed technical documentation is provided in Pizer et al. (2003). ${ }^{3}$ The following subsections describe these models in greater detail.

\subsection{Electricity Model}

The Haiku electricity sector model is a simulation model that describes regional electricity markets and inter-regional electricity trade with an integrated algorithm for investment and retirement of generation capacity, fuel choice, and mission control technology choice. ${ }^{4}$ The model uses iteration to converge to market equilibria and calculate electricity demand, electricity prices, the composition of electricity supply, and emissions of key pollutants such as $\mathrm{NO}_{X}, \mathrm{SO}_{2}, \mathrm{CO}_{2}$, and

3. We also developed estimates of energy-price responsiveness in the commercial sector using a discrete-continuous choice model of multi-fuel energy demand (Newell and Pizer 2003).

4. Haiku has been used for a number of reports and articles, for example, Burtraw et al (2003; 2003) In addition, the model has been compared with other simulation models as part of two series of meetings of Stanford University's Energy Modeling Forum (1998; 2001) and is documented in Paul and Burtraw (2002). 
$\mathrm{Hg}$ from electricity generation. The model solves for the quantity and price of electricity delivered in 13 regions, for four time periods in each of three seasons. For each of these 156 market segments, demand is aggregated from three customer classes: residential, industrial, and commercial. Supply is aggregated from the complete set of electricity plants in the United States, which for modeling purposes are aggregated into 48 representative plants in each region. Investment in new generation capacity and retirement of existing facilities are determined in a dynamic framework, based on capacity-related costs of providing service in the future. Generator dispatch in the model is based on the minimization of short run variable costs of generation.

Inter-regional power trading is identified at the level of trading necessary to equilibrate regional electricity prices (accounting for transmission costs and power losses), constrained by the assumed level of available inter-regional transmission capability as reported by the North American Electric Reliability Council (NERC). Factor prices, such as the cost of capital and labor, are held constant. Fuel price forecasts are calibrated to match EIA price forecasts for 2002 (EIA 2001). ${ }^{5}$ Fuel market modules for coal and natural gas calculate prices that are responsive to factor demand. Special attention is given to the flexible modeling of institutions in the electricity sector, both with regard to the way prices are set (regulated versus competitive regional electricity markets) and the design of environmental regulations.

\subsubsection{Policies in the Electricity Sector}

The policies that reduce emissions at the least cost in the Haiku model of the electricity sector are an emission tax or a cap-and-trade policy. These are equivalent policies assuming that emission permits are distributed initially through an auction, and assuming the absence of uncertainty and symmetric accounting rules. Hence we refer to them jointly as a "carbon price" policy. We analyze policies implemented for the year 2010. We find the carbon price produces a roughly concave marginal abatement cost schedule given a constant level of electricity demand.

Under a carbon price policy, the largest source of emission reductions comes from coal generation, which accounts for $86 \%$ of electricity sector carbon emissions in the baseline and falls by up to one-quarter in absolute terms over the range of policies we examine. For initial (low) levels of the carbon price, reductions in emission from coal account for about three-quarters of total reduction. At a price of $\$ 100$ per ton of carbon (1999\$), reductions in coal account for all emission reductions while natural gas emissions actually increase (though coal still accounts for $80 \%$ of total emissions). The inflection point where natural gas emissions begin to increase occurs at a carbon price of $\$ 40$. Among natural gas generators, we find a shift in the type of gas capacity, with substitution away from

5. More recent fuel price forecasts are similar for coal but show an increase in natural gas prices. About $40 \%$ of the increase in natural gas price forecasts that have been incorporated in EIA analysis between 2000 and 2004 were present in the forecast for 2002 . 
gas turbines and toward combined cycle generation, which has lower emission rates. The percent increase in combined cycle rises with carbon price levels.

We also examine a RPS implemented at a national level, which is a sector-specific technology policy. Qualifying technologies include existing and new wind and biomass electricity and exclude hydroelectric, approximating many of the existing state policies as well as the RPS proposal that was removed from the Senate version of 2005 U.S. Energy Policy Act during the conference process. Policy targets identified the portion of total generation to come from renewables, up to $22.5 \%$. Tradable RPS credits effectively constitute a subsidy per kWh necessary to achieve this contribution from renewables, and reached as high as $\$ 0.20$ per $\mathrm{kWh}(1999 \$)$. The charge per unit of generation from nonrenewable sources reached $\$ 0.05$ per $\mathrm{kWh}$ at this extreme, more than doubling the price of generation from nonrenewable sources. The electricity price increases by $30 \%$ in the extreme case. ${ }^{6}$

The RPS is an inefficient policy for achieving reductions in carbon compared to the carbon price policy because it penalizes all nonrenewable generation in a similar manner (Palmer and Burtraw 2005). In fact, we see some perverse consequences of the RPS. For instance in moving from an RPS of $10 \%$ to the extreme policy target of $22.5 \%$, coal-fired generation falls by 370 billion $\mathrm{kWh}(17 \%)$ but gas-fired generation also falls by 138 billion $\mathrm{kWh}(23 \%) .{ }^{7}$ Similarly, coal-fired capacity falls by $36,800 \mathrm{MW}$ while gas-fired capacity also falls by 29,900 MW. Meanwhile non-hydro renewables increase by 349 billion MWh (74\%) and, accounting for a lower rate of capacity utilization, renewable capacity increases by 98,700 MW. ${ }^{8}$ Furthermore, although the effect is small, we actually see a decline in generation from relatively efficient natural gas units compared to less efficient (peaking) gas units. This is because the renewables have low variable costs and typically are used the maximum amount of time they are available, which places renewables in competition with combined cycle units in baseload time blocks. An RPS may achieve other policy goals, such as helping to overcome inherent bias in the current configuration of the transmission grid that favors central power stations. And like a carbon price, it also leads to ancillary reductions in other air pollutants (Burtraw, Krupnick et al. 2003). Nonetheless, it is less cost-effective than a carbon price in reducing carbon emissions. The relative cost-effectiveness of these policies is described in the general equilibrium analysis.

6. Palmer and Burtraw (2005) perform an analysis of an RPS using more recent and complete characterizations of renewable technology and more recent fuel prices. They find the charge per unit of generation from nonrenewable sources rises to $\$ 35$ at a $20 \%$ RPS, with electricity rising by only $8 \%$.

7. Generation is based on short run variable cost. If renewable capacity is built, given its low variable cost, it will run up to its maximum utilization rate. Wind resources are characterized spatially but not temporally, so wind generation is distributed over all time blocks and displaces different fuels in each time block, depending on what is the marginal fuel. Although coal is the major fuel in the base time block, typically gas is the marginal fuel for new capacity, so there is some substitution for each depending on the region of the country and season.

8. At a $10 \%$ RPS target, wind constitutes $82 \%$ of renewable generation and biomass is $10 \%$. At the $22.5 \%$ RPS target, wind is $65 \%$ and biomass is $30 \%$. 


\subsection{Transportation Model}

The U.S. household transportation model consists of a vehicle production sector, household vehicle demand and use, and a scrappage market (Harrington et al. 2003). The model is designed to investigate both short- and long-run household responses to policies aimed at reducing carbon emissions. For example, in the short run, we would expect households to drive fewer miles if the cost per mile of travel is increased, with the magnitude of the reduction depending on the elasticity of vehicle miles traveled (VMT) with respect to price per mile. Over time, households will most likely respond to changing vehicle prices and fuel costs from carbon policies by altering the number and types of vehicles owned. In fact, many argue that CAFE standards will not only change the relative prices of new vehicles by class, but could also change the relative prices of new and used cars (Kleit 1990; Kwoka 1983; Thorpe 1997). By decreasing driving cost, furthermore, it has also been observed that higher fuel economy will lead to increased VMT, a phenomenon often called the "rebound effect."

The dynamics of the model follow from the carryover of vehicle stocks from one period to the next. For example, part of the stock of new cars and trucks in period $T$ are added to the stock of old vehicles in period $T+1$. Within each period, households demand new and old vehicles based on their relative prices and operating costs per mile. Automobile producers respond by producing new cars and trucks, where we assume that producers are price-takers and the production technology is constant returns to scale. We also simplify the producer's cost function, assuming costs vary only with changes in fuel economy. The supply functions for old vehicles are the scrappage functions, where the scrappage rate depends on the price of old vehicles and their scrap value.

Our household demand model is a simpler version of the model employed in Train (1986), which is based on expected utility theory and estimated using discrete/continuous choice econometric models (Dubin and McFadden 1984). The main simplification is that we limit the number of class/vintages to four; new car, new truck, old car and old truck where the truck classification includes vans, pickups and sport utility vehicles. This simplified model is nonetheless sufficient to display the range of relevant responses of motorists to the policies of interest, i.e. fuel taxes and changes to fuel economy standards.

Household vehicle demand is based on a nested multinomial logit model (NMNL) of vehicle choice that uses data from the 1990 Nationwide Personal Transportation Survey. The decision on how many vehicles to own is estimated in the top-level of the nest and vehicle class/vintage choices are estimated in the second-level. Using the predicted probabilities from the NMNL estimation as a sample selection correction, we estimate VMT conditional on number of vehicles owned using a log-log specification. ${ }^{9}$ Simultaneous estimation of this discrete/

9. We estimate the model sequentially where we first estimate a nested multinomial logit model of the numbers of vehicles to own $(0,1,2$, or 3$)$ and the class/vintage of each car and then conditional on these choices; we estimate a model of vehicles miles traveled (Train 1986; Goldberg 1998). We also do not restrict the coefficients on the common variables to be equal across the choices (Harrington et al. 2003) 
continuous model imposes a number of constraints on model parameters. However, our model, like almost all discrete/continuous models of vehicle stock and use, estimates the discrete model and the continuous model separately and does not impose these parameter restrictions. This greatly simplifies estimation, but it means that the resulting demand equation is not integrable, which in turn means that it is impossible to calculate policy costs in a theoretically consistent way.

\subsubsection{Policies in the Transportation Sector}

The dynamic household transportation model is capable of looking at many realistic scenarios associated with implementing CAFE and fuel taxes. For example, if the goal is to reach a certain emission reduction in some year using a CAFE policy, the regulator can vary the phase-in rate to meet such a goal. Because CAFE affects the use of vehicles only indirectly via changes in the vehicle stock, the phase-in rate can significantly affect the cost of the policy; faster rates of increase over shorter periods of time are associated with greater price increases in vehicles.

We simulate constant percent increases in CAFE standards or fuel prices over a five-year period, after which CAFE regulations or tax rates are held constant for an additional ten years. ${ }^{10}$ The advantage of the detailed sector model is that it estimates readily observable physical quantities, such as change in new and old vehicles, cars and trucks, age of vehicles, and vehicle miles traveled. The standards we model differentiate between cars and trucks, as do actual CAFE standards. One efficiency advantage of fuel taxes relative to CAFE is that fuel taxes do not differentiate between vehicle types. However actual CAFE standards do not allow for trading among manufacturers, but we allow such trading, which improves the performance of CAFE in the model relative to actual policy.

We find a number of qualitative differences in the performance of the two types of policies. First and foremost, CAFE and fuel taxes achieve their emission reductions in different ways, and fuel taxes are more efficient in reducing fuel use and emissions because fuel taxes operate on three margins to reduce fuel use: total vehicle ownership, use per vehicle, and improved fuel economy. For example, a five-year annual gas price increase of four percent produces a five percent reduction in fuel use by year 15 . Most (85 percent) of this reduction is due to reduced vehicle use. On the other hand CAFE operates directly only on one margin, improved fuel economy. For CAFE, the five percent reduction is accomplished by a two percent annual increase in CAFE over five years. At the end of the period the change in fuel economy is 16 percent greater than the change in fuel use, because vehicle use actually increases due to the rebound effect.

CAFE and fuel taxes also differ in their effect on the structure of the fleet. Both have slight negative effects on the number of vehicles, but the reduc-

10. See Harrington et al. (2003) for additional analysis and discussion around policy simulations. The waiting period allows time for the CAFE policies to ripple through the vehicle stock. The longer the period until the evaluation occurs (after the ramp-up period), the lower the costs of CAFE in meeting a certain target level of emissions. 
tions differ across the vehicle stock. ${ }^{11}$ For instance, we find that in the gasoline tax scenarios the number of cars stays constant or increases slightly; the entire decline in number of vehicles comes from trucks, especially older trucks. In the CAFE scenarios, there is a substantial increase in old trucks and a corresponding decrease in new cars. Old cars and new trucks are largely unaffected. As a result of these fleet shifts, the life expectancy of both cars and trucks increases under $\mathrm{CAFE}$ and declines in the fuel tax scenarios. CAFE raises new vehicle prices substantially, reflecting the improvements in fuel economy. As Kleit (1990) predicts, used car prices also rise, with increases on the order of $14 \%$ for cars and $8 \%$ for trucks. Finally, due to stock turnover rates and rebound effects, a major difference between CAFE and fuel economy policies is the speed with which the policies achieve a certain level of emissions reduction.

\subsection{Industrial Sector Model}

The industrial sector model is based on the National Energy Modeling System's industrial sector demand module (EIA 1999). The industrial sector model distinguishes 15 industry groups, for which it forecasts the demand for 13 main fuels in four geographic regions. The model covers energy demand from both manufacturing (SIC 20-39) and non-manufacturing sectors (SIC 1-2, 10-17), with industry group classifications chosen to be as consistent as possible with the Manufacturing Energy Consumption Survey. The model estimates the quantity consumed of each fuel along with non-utility electricity generation and corresponding steam production. Unlike the electricity and transportation models, the industrial sector model takes output levels as fixed. The model calculates carbon emissions based on the carbon contents of the fuels used.

We chose to base the industrial sector on the NEMS industrial demand module for several reasons. First, the NEMS industrial module has, to our knowledge, undergone more development effort, peer review, and testing than any other model of U.S. industrial energy demand. It also offers a straightforward platform for assessing the carbon reductions associated with a carbon price or carbon permit system. Finally, the module's technology and sectoral detail is sufficiently disaggregated to allow estimation of the emission and fuel use consequences of non-price policies (e.g., uniform performance standards) and price and non-price policies targeted to specific sectors or components of energy demand.

11. The relative performance of CAFE and fuel taxes might differ slightly were we to assume something other than perfect competition in vehicle fleet production. CAFE raises the price and tends to reduce the demand for new vehicles while an increase in fuel prices would tend to increase the demand for new vehicles. In a model where producers had market power, we would have different baseline conditions. Since the baseline is calibrated to observed vehicle holdings in year 0 , consumers would have to have a greater relative demand for new vehicles if producers are assumed to have market power. It is difficult to say a priori whether fleet turnover would be more or less sensitive to changes in fuel taxes in this case, but we are confident that the effect is small. Moreover, at least over the planning horizon used here, in the model fuel tax increases influence fuel use more through reductions in vehicle use in all vehicles rather than improved fuel economy in new vehicles. 


\subsubsection{Policies in the Industrial Sector}

The model is capable of computing any number of different carbon price scenarios, as well as uniform percent emission reduction standards by industry. The carbon price is levied on fuel use, and reflected in fuel prices, as if the carbon price is levied on fuel suppliers, but they are able to pass $100 \%$ of the carbon price onto their industrial consumers. As the model does not contain foresight, to approximate the effects of foresight we levy the carbon price beginning in the year 2000 and evaluate results as of 2010.

We use the industrial sector model to simulate both a uniform carbon price and a "uniform percentage rollback" in the industrial sector. Figure 1 illustrates our results for the costs of carbon mitigation for the industrial sector. The results show that for a carbon price policy, based either on a carbon tax or tradable permit system, the marginal cost of carbon mitigation rises at an increasing rate, with a 5\% reduction in emissions costing about $\$ 65 /$ ton $(1997 \$)$. The "uniform percentage rollback" policy evaluates a series of percentage emissions reductions by industry group for manufacturing industries. Policy costs and emissions changes are calculated for each percentage level for each industry group. The resulting marginal cost curve for all of industry is higher than for the more efficient price policy - about 50\% more expensive on the margin for a $5 \%$ reduction in emissions, reflecting the difference in the cost of carbon reduction across industrial sectors. In the actual economy, if the rollback policy approach raised costs more we would expect to see a greater change in product prices as well, and demand would decrease. Since the output is held fixed in the model, this margin is not available and we probably overestimate slightly the relative cost of the rollback policy relative to the uniform carbon price.

\section{Figure 1. Marginal Cost of Carbon Reductions in U.S. Industrial Sector}

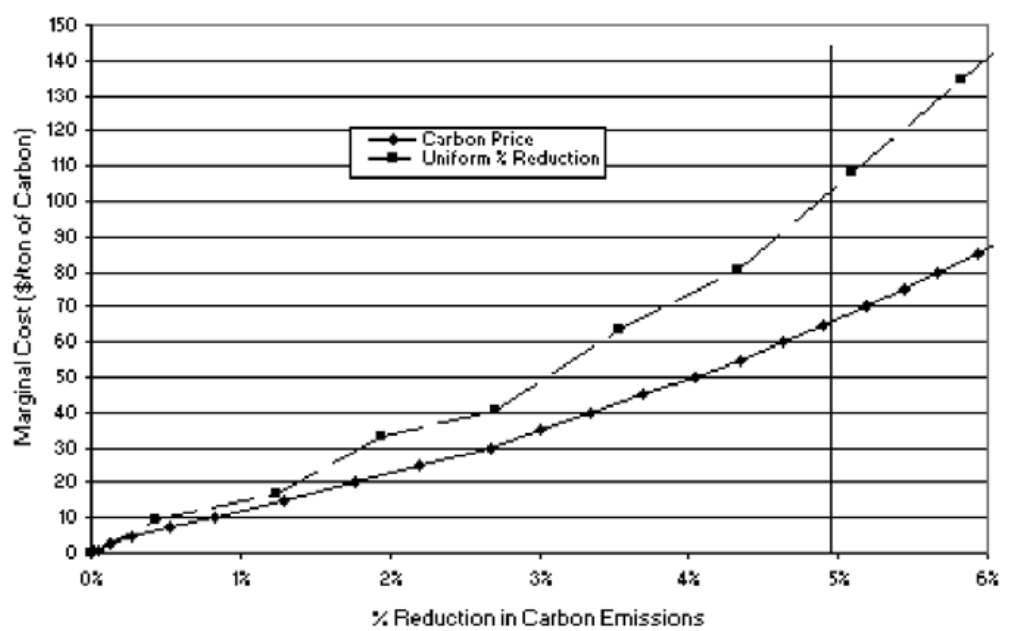




\section{ADOPTING DETAILED SECTORAL MODELS FOR GENERAL EQUILIBRIUM USE}

Economy-wide general equilibrium models are the workhorses of economic studies of carbon price policies (i.e., taxes or tradable permits systems). The reasons for using such models are frequently noted: they provide the capacity to study the effects of carbon prices in the economy in a way that is consistent with economic theory, consistent across sectors, and cognizant of inter-sectoral interactions across goods and factor markets. General equilibrium models applied to energy-economy- $\mathrm{CO}_{2}$, however, often lack detailed technology-rich description of energy demand (e.g., for personal transport or in buildings). ${ }^{12}$ They also have a limited ability to handle policies that do not readily reduce to a single carbon price, such as sectoral price policies that vary across sectors, or non-price policies that encourage, mandate, or forbid certain choices. Energy efficiency standards are a canonical example. As we discuss further below, in principle any such policy can be reduced to an equivalent set of price distortions, but without a fair amount of sectoral detail, it may be far from easy to ascertain the relevant price-equivalent representation.

Detailed sectoral models have the advantage of facilitating analysis of such policies by replicating more fully key technology choices and institutions and features associated with particular types of economic activity. However, it is hard to use these models to develop a picture of overall economic impacts or impacts in other sectors. Specifically, sectoral models cannot calculate overall policy costs simultaneously in all markets.

Ideally, one might imagine patching together a collection of detailed sectoral models into a single, economy-wide model capturing simultaneous equilibria in all markets. Several efforts have attempted this in one manner or another. Böhringer (1998) and Böhringer and Rutherford (2005) show how smooth production functions can be combined with discrete technologies in models solved using mixed complementarity algorithms in a static context; Frei et al. (2003) extend this to a dynamic setting. Jaccard et al. (2003) take a different approach, modifying a general equilibrium model so that it can replicate the general range of results from both types of models— those with and without technology detail—by making substitution among technologies smoother and adjusting the sometimes favorable engineering-based technology costs. McFarland et al. (2004) perhaps provide the most thorough example of combining both types of models, inserting specific technologies such as capture and sequestration in a dynamic general equilibrium model.

12. Within this class of models, the details can vary substantially (for discussion of model differences see Weyant and Hill (1999) and Ghersi and Toman (2003)). For example, some of these models were originally developed to study energy-related issues; they have a relatively large amount of detail in the description of energy supply, but little breakdown of the rest of the economy. Other models have relatively less energy detail (e.g., describing electricity supply) but more detail on other goods markets. 
Yet even when discrete technologies are included in economywide models, they continue to miss details difficult to capture in a model seeking economywide general equilibrium. The Haiku electricity model described above predicts generation at the facility level and tracks 156 time, season, and regionally differentiated kinds of electricity, for three customer classes. Meanwhile, the transport model predicts vehicle choice and use for a large sample of representative households. This kind detail cannot be maintained in an economywide model. Detailed sectoral models are usually a combination of simulation and optimization. Simulation models allow policy effects to propagate through a very large number of relationships in an iterative calculation. Coupling such models with similarly detailed models in other sectors and searching for a simultaneous equilibrium is unrealistic due to the computational requirements.

Still, the advantage of putting the detailed models together is the calculation of overall policy costs. An alternative to trying to merge detailed sectoral models with aggregate economywide models and keep their technological detail, as the aforementioned authors have sought to do, is to use traditional CGE representations of the sectoral models calibrated to the detailed model results. Combined in a simple economywide model, they can provide consistent estimates of aggregate costs even as the detailed, stand-alone sectoral models are simulated to reveal detailed impacts and examine non-price policies. ${ }^{13}$ That is, while other authors have sought to put increasing amounts of technology/sectoral detail into an economywide model, discarding whatever cannot fit in the economywide model, we keep the economywide model simple but calibrated to detailed sectoral models and keep using the detailed sectoral models. The lingering use of detailed models allows us to model non-price policies based on the detailed model response, rather than a simplified representation.

\subsection{Modeling Integration}

For each detailed sectoral model, our approach is to construct a similar reduced-form sectoral model based on the benchmark 1992 National Income and Product Accounts (NIPA) of the United States (Lawson 1997). ${ }^{14}$ We use simulations of the detailed sectoral models to calibrate elasticities in the reduced-form model. We use a nested constant elasticity of substitution (CES) functional form for the reduced form models. The top nest involves substitution between capital, labor, energy, and materials (KLEM). Energy inputs-coal, petroleum, natural gas, and electricity - comprise one sub-nest. The remaining commodities comprise the material sub-nest. We assume that materials have zero elasticity of sub-

13. In sectoral models where aggregate economic conditions are exogenous, it is possible to consider changes in those conditions by iterating simulation of the sectoral model and an aggregate economic model. See, for example, (1998).

14. We simulate the detailed sectoral models in 2010, creating an inconsistency between the 1992 input-output data being used in the general equilibrium and the forecasted 2010 input-output relations in the detailed sectoral models. We note in several places where consequences of this inconsistency arise. 


\section{Figure 2. Nested CES Structure for Each Production Sector}

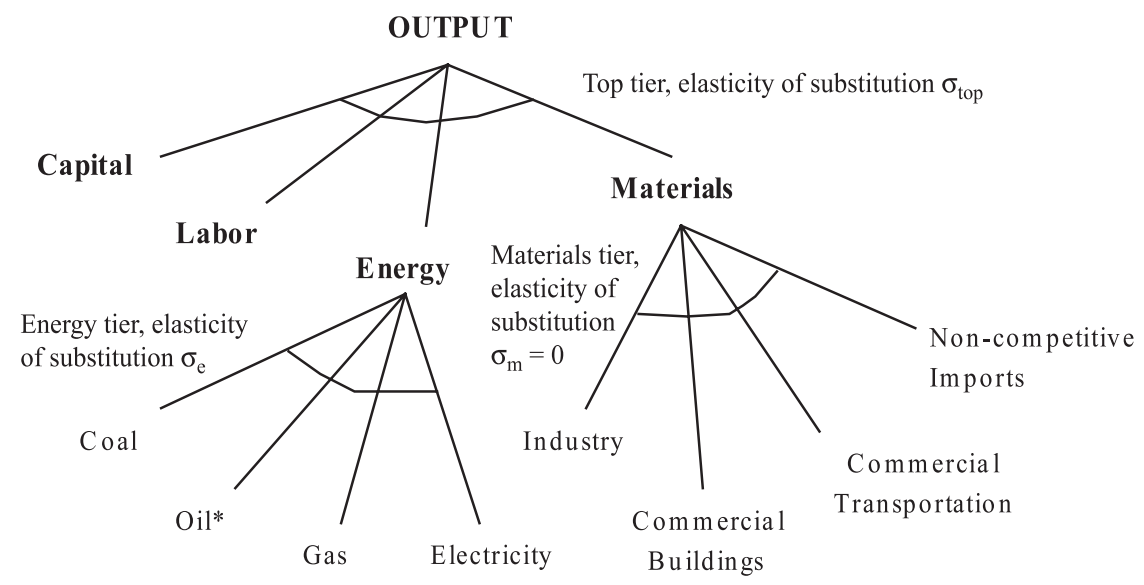

* Oil is included in the materials tier for the household transportation services sector to allow fuel and fuel delivery services to be combined in a sub-tier before combining with capital in the top tier.

stitution among one another and use simulations of the detailed sectoral models to determine the energy $\left(\sigma_{e}\right)$ and KLEM $\left(\sigma_{t o p}\right)$ elasticities. ${ }^{15}$ The nested CES model is illustrated in Figure 2.

To determine the elasticities in the electricity, household transportation, industry, and commercial building sectors, we simulate the effect of a carbon price on use of fossil fuels and electricity in the appropriate detailed sectoral models. With a schedule of simulated data points between zero and about $\$ 60$ per ton of carbon, we attempt to match these detailed sectoral model results with the percentage changes in fuel demand predicted by the reduced-form model using the same percentage changes in fuel prices. We focus on this range because it represents the range of prices relevant for the policies we eventually consider. ${ }^{16}$ Elasticities are chosen for each sector to minimize the sum of squared errors in percent changes in fuel and other available inputs given by the reduced-form model compared to

15. Household transportation is treated differently, because it does not exist in the input-output accounts. We create it from a combination of household purchases of gasoline and an imputed capital stock. Household purchases of gasoline are separated from home heating oil based on Table 2.2, 1992 National Income and Product Accounts (from the BEA website; see BEA 2002). The imputed capital stock of household vehicles is based on the ratio of consumer vehicles capital stock to total private capital in 1992 from Table 1.1 of the detailed data on fixed assets and consumer durable goods (from the BEA website; see Herman 2000).

16. The number of data points used ranges from 8 to 15 with the exception of electricity, which uses 1, where each "point" includes predictions of multiple inputs. Because the model focuses on percent deviations from the benchmark of a zero carbon price, the deviations are necessarily larger at higher carbon values and the estimation is driven by the upper endpoint-making the number of data points less important. Because behavior in the electricity sector is difficult to capture in our reduced form model (discussed later), we were unable to fit the data with more than one point. 
the detailed sectoral model results, weighting by expenditure. That is, we choose the elasticities $\sigma_{e}$ and $\sigma_{\text {top }}$ to minimize

$$
\Sigma_{e, n}\left(w_{e}\left(x_{e, n}-\bar{x}_{e, n}\right)\right)^{2}
$$

by searching over various combinations of these two parameters. Here the summation is over both $e$ inputs (including combinations of coal, oil, natural gas, electricity, capital, and labor) and $n$ distinct simulated carbon prices. The variable $x_{e, n}$ is the percent change in use of input $e$ for carbon price $n$ predicted by the reduced form model, $\bar{x}_{e, n}$ is similarly the predicted change in the detailed sectoral model, and $w_{e}$ is the expenditure on input $e$ in the reduced form model (from the input-output tables). The household transportation sector is somewhat different than the others in that we use detailed sectoral model results to estimate a KLEM elasticity and an elasticity of substitution between household transportation and consumption of other market goods. Estimated elasticities are shown in Table 1 along with goodness of fit statistics.

\section{Table 1. CGE Elasticities Estimated from Detailed Sectoral Models}

\begin{tabular}{lccc}
\hline Sector & KLEM elasticity & Energy elasticity & Estimated Fit $\left(\mathbf{R}^{2}\right)$ \\
\hline Electricity & 0.09 & 0.07 & $0.20^{* *}$ \\
Industry & 0.15 & 0.29 & 0.99 \\
Commercial buildings & 1.19 & 0.29 & 0.98 \\
Transportation $^{*}$ & 0.24 & 0.00 & 0.99 \\
\hline
\end{tabular}

* Note that the elasticity between household transportation and consumption of other market goods, also estimated from the detailed transportation model, is 0.34 .

** Estimated fit rises to 0.56 when oil demand in the electricity sector is excluded from the $\mathrm{R}^{2}$ calculation. In HAIKU, oil is a much smaller share of generation than the benchmark data from 1992 and its behavior is somewhat suspect.

With the exception of the electricity sector, we fit the data exceedingly well. This reflects the smooth behavior of substitution in the industrial, transport, and commercial building sectors, as well as the fact that we are only fitting two factor demands in transport and three in commercial buildings. We are fitting four factor demands in the industrial sector, but most of the variation is in just two; coal and electricity both vary by about 30 percent over the range of simulations while gas and oil vary by only a few percent. Getting the changes in gas and oil 75 percent right only leaves an error in demand of one or two percent. Electricity is much harder to fit, a point we discuss below.

While we fit changes in individual fuel use based on changes in fuel prices, our ability to match the carbon dioxide abatement schedule also is important given our interest in policies to reduce carbon dioxide emissions. Even with a close fit based on Equation, deviations are possible because the reduced form model necessarily uses cruder measures of carbon content. While the detailed 
sectoral models track physical quantities, the reduced-form model relies on inputoutput accounts that only contain dollar flows. Carbon content is assigned to the dollar flows coming from coal, natural gas utilities, and petroleum refining based on emission data by fuel and major sector-transportation, residential, commercial, industry, and electricity. ${ }^{17} \mathrm{It}$ is also likely that the mix of fuels differs between the reduced-form model, based on the 1992 input-output tables, and the detailed sectoral models, based on a variety of more detailed sources forecast in 2010.

Figure 3 compares the $\mathrm{CO}_{2}$ marginal abatement cost schedules from the detailed sectoral models to the schedules from the reduced-form models for the four sectors we fit. ${ }^{18}$ The reduced-form schedules for commercial buildings and transportation come out slightly less elastic than the detailed model results; industry a bit more elastic. The errors in marginal cost for a given level of reductions are on the order of a few percent in buildings and transportation and closer to $25 \%$ for industry. The reduced-form marginal cost schedule for electricity does not provide as good a representation of the cost curve from the detailed electricity sector model. While they match at around $\$ 60$ per ton, the detailed model shows a concave schedule and the reduced-form a convex schedule. The concave schedule arises in the detailed electricity model because significant supply-side reductions do not begin to appear until the relative cost of coal rises sufficiently. At low levels of a carbon tax we see reductions in emissions from coal and existing relatively inefficient gas-fired facilities. Gas use is at a minimum at a carbon price of $\$ 60$ but then rebounds with increased investment in more efficient facilities (see also discussion in the electricity modeling section). Yet, a CES production function cannot capture a concave schedule.

\subsection{Non-carbon-price Sectoral Policies}

In addition to using the detailed sectoral models of electricity, household transportation, commercial buildings, and industry to fit elasticities in reduced-form nested CES models, we also develop an approach to model non-price policies, including CAFE standards, industrial performance standards, and renewable electricity performance standards. While it is relatively straightforward to simulate these policies in the detailed models, previously it has not been clear how can they be represented in a reduced-form CES model. By suggesting a way to model them in a reduced-form manner, our approach opens the door for substantial further analysis.

Simulation results from the detailed models provide data on how production changes in response to these policies-that is, changes in inputs and outputs

17. Based on our assignment of carbon flows from the Annual Energy Review to sectoral \$ flows from NIPA, carbon content for coal ranges from 21 to 29 tons per thousand dollars, for petroleum from 0.7 to 8.0 tons per thousand dollars, and for natural gas from 0.9 to 9.0 tons per thousand dollars. The value depends on the quality of the product (for example, gasoline is a higher quality product than fuel oil) and the bargaining power of the purchaser (coal and natural gas prices are lower for electricity generators compared to industrial users).

18. Note the reduced-form model results in Figure 3 are based on the price and output changes given by detailed sectoral model simulations to which they are being compared. 
Figure 3. Comparison of Emission Reduction Schedules for Reduced-form and Detailed Sectoral Models

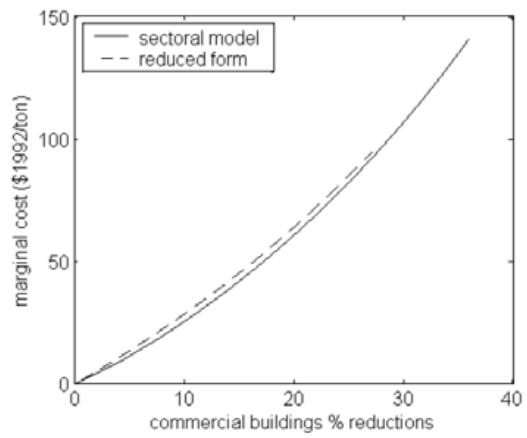

commercial buildings

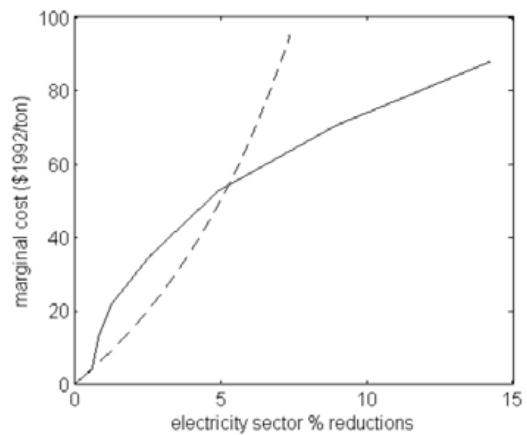

electricity

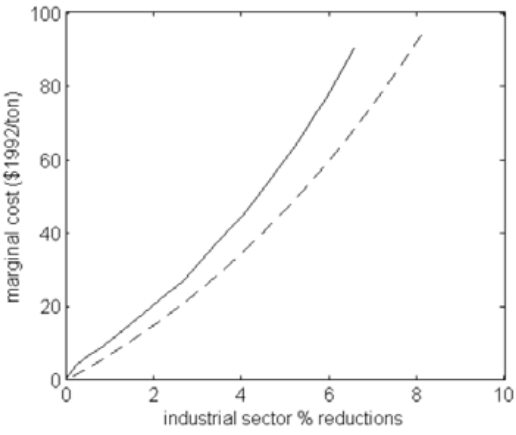

industrial sector

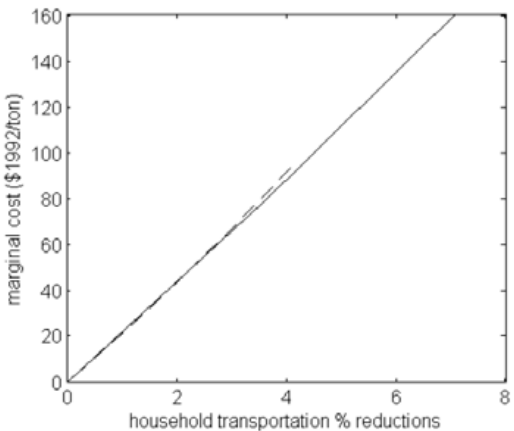

household transportation

at different levels of CAFE or an RPS. There are several ways we could imagine replicating these results in a reduced-form model. Without changing the model parameters, we could impose constraints that shift production while prices remain the same. For example, fuel economy requirements on automobiles and renewable electricity standards both suggest a maximum ratio of fossil fuel to output.

We could also imagine using a different production technology to generate the new policy outcome. That is, we could change the technology of production by changing the CES parameters (elasticities, initial input shares, or productivity) so that the new RPS or CAFE outcome arose at benchmark prices. Both of these approaches require us to change the shape of the production possibility frontier, either explicitly or through constraints, to cause input use to shift in response to non-price policies. 
Rather than changing the production frontier, suppose we imagine instead that firms suddenly saw the internal cost of using particular inputs diverging from market prices. For example, a fuel economy standard would make transportation fuel use appear more costly (relative to capital) to firms and households because fuel consumption uses up flexibility with respect to the standard. Perhaps a better example is an RPS, where the use of fossil fuels to generate electricity actually becomes relatively more costly than capital-intensive renewables because the former requires RPS credits and the latter generates them.

All of this suggests modeling non-price policies as a change in the prices contemplated by the firm, even as the market prices and underlying technology remain unchanged. This is straightforward to implement as a system of taxes and subsidies on inputs and output that creates no net revenue-for example, taxing fuel and subsidizing output in such a way that they balance out. If no net revenue is generated, net price continues to equal net input costs. This is true despite the fact the taxes and subsidies change the implicit prices used by the firm to configure their production strategy.

We call these shadow taxes because they do not really tax the firm on net, but change the relative price of inputs. This approach can further allow for a Hicks neutral productivity shock-requiring proportionally more inputs for a given output level—because in some cases policies might not only shift input usage along a production frontier but also lead to inefficient use of existing technology. The shadow taxes move the choice of inputs along the production function, and the productivity shock shifts production to an interior, inefficient level of output. ${ }^{19}$

The shadow tax approach seems particularly appropriate for flexible performance standards, like tradable CAFE (National Research Council 2002) and an RPS, where the policies place no limit on the scaling up or down of total production. Instead, these policies pressure input usage in particular directions. The idea that such policies appear, from the producers' perspective, as an effective tax on fuel use and subsidy to capital use actually makes sense (Fischer and Newell 2004). A key feature in both the policies and the shadow tax approach is that, unlike cap-and-trade or carbon tax policies directed at emissions, these policies do not price inframarginal emissions.

In practice, we estimate the vector of taxes, subsidies, and productivity shocks in a manner analogous to estimation of the CES elasticities. Data from each of the detailed models is in matched, as closely as possible, to predictions from the reduced-form model by minimizing the squared error in Equation through the choice of a set of taxes, subsidies, productivity shocks, and scaling factors, given the previously estimated CES elasticities. ${ }^{20}$ The scaling factors allow us to

19. As we note below, we do not find evidence of such negative productivity shocks when we examine the sectoral data.

20. As with the carbon tax, we choose a range of policy values consistent with the policies eventually considered. For the RPS, this includes 7 standards up to 22.5 percent; for CAFE, four sets of standards representing 10, 20, 30 and 40 percent improvements for cars and light trucks. The industrial sector policy of equal percent reductions is run from 1 to 12 percent at 1 percent increments. 
Table 2. Ad Valorem Shadow Taxes (+) and Subsidies (-) for Simulating Non-price Policies

\begin{tabular}{|c|c|c|c|}
\hline & $\begin{array}{c}\text { CAFE } \\
\text { standards }\end{array}$ & $\begin{array}{c}\text { Renewable } \\
\text { electricity } \\
\text { standards }\end{array}$ & $\begin{array}{c}\text { Industry uniform } \\
\% \text { reduction } \\
\text { standards }\end{array}$ \\
\hline Coal & $\mathrm{n} / \mathrm{a}$ & 0.83 & 0.82 \\
\hline Oil & 0.25 & 4.2 & 0.096 \\
\hline Natural gas & $\mathrm{n} / \mathrm{a}$ & 4.8 & 0.18 \\
\hline Electricity & $\mathrm{n} / \mathrm{a}$ & $\mathrm{n} / \mathrm{a}$ & 0.31 \\
\hline Capital & -0.24 & -0.66 & -0.0054 \\
\hline Labor and materials & $\mathrm{n} / \mathrm{a}$ & -0.48 & -0.0054 \\
\hline Output $^{3}$ & 0.00 & 0.04 & 0.00 \\
\hline Productivity shock & 0 & 0 & 0 \\
\hline Policy level (\% carbon reduction) & $9 \%^{1}$ & $7 \%{ }^{2}$ & $6 \%$ \\
\hline Estimated Fit $\left(\mathrm{R}^{2}\right)$ & $1.00^{4}$ & 0.82 & 0.99 \\
\hline
\end{tabular}

${ }^{1}$ The reference CAFE policy is a $22 \%$ increase in fuel economy, to roughly $29 \mathrm{mpg}$ fleet average.

${ }^{2}$ The reference RPS policy is a $10 \%$ renewable electricity standard.

${ }^{3}$ The output tax/subsidy is reported for reported given policy level, but is endogenously determined as other taxes and subsidies are scaled.

${ }^{4}$ We can fit CAFE exactly because there are only two demands (gasoline and capital) being predicted, and they are only predicted relative to each other. A fixed distortion between capital and gasoline, coupled with a scaling parameter for the policy aggressiveness associated with each CAFE run in the detailed model, can exactly replicate such changes in relative demands.

use data from a range of stringency scenarios associated with each policy, jointly scaling the shadow taxes and subsidies for each scenario. Note that the estimated parameters, shown in Table 2, reflect the non-price policy operating at the particular level indicated in the next-to-last row. In our CGE simulations, as in the fitting exercise, we jointly scale the input taxes and subsidies in order to achieve different emission goals, while the output tax or subsidy endogenously adjusts to maintain zero-net revenue from the distortions.

The bottom row of Table 2 shows that, as in the elasticity fitting exercise, we are able to fit the observed data extremely well except for electricity, where behavior is more complex. The results on the second to last row indicate no productivity effects associated with the various inefficient policies — only shifts along the production frontier due to the shadow taxes and subsidies. This may be because there are, in fact, no productivity effects. It may also arise because in some of the detailed models (household transportation and industry) we do not have measures of overall cost — only responses for a subset of inputs and outputs. ${ }^{21}$ This makes it more difficult to identify lost productivity. The productivity effects may also be small relative to the shifts along the production frontier. Effects on the remaining inputs are sensible. Energy prices increase relative to other inputs. For industry performance

21. The household transportation model does not provide a sectoral output measure-e.g., transportation services - and makes predictions holding income constant. Without a utility measure, there is no analog to cost. 
standards, coal prices increase more than oil, which increases more than natural gas. For the RPS, we see that coal prices increase less than oil and gas-reflecting the earlier observation that an RPS tends to displace gas rather than coal.

\subsection{Additional CGE Model Details}

The description so far has focused on our modeling of four sectorselectricity, industry, commercial buildings, and household transportation-and on the application of policies to three of those sectors..$^{22}$ To complete the CGE model, we need to model other productive sectors, including the fossil fuel supply sectors, final demand from consumers, investment, and government, foreign supply and demand, and factor supply.

The CGE model is centered around eight production sectors, distinct household and government agents, investment, and a standard model of relatively inelastic import supply and elastic export demand. The eight production sectors provide particular detail on fossil fuel use (coal, petroleum, natural gas) in order to monitor carbon dioxide emissions. The structure separates electricity generation, industry, commercial buildings, household and commercial transportation for more detailed policy modeling. Our household transportation sector combines household capital (cars), gasoline, and retail services into a good consumed exclusively by the household. This allows us to model CAFE policies. The exact composition of these sectors based on Input-Output Classification Codes is given in Pizer et al. (2003), along with the intersectoral flows of goods. The model is benchmarked to the 1992 National Income and Product Accounts (from the BEA website; see BEA 2002).

In its comprehensive representation of the U.S. economy, this model captures all energy and fossil fuel use, even those uses that have not been the focus of our more detailed modeling efforts. Government use of energy, for example, is captured along with commercial transportation, and investment (mostly construction).

Following Kehoe and Kehoe (1994), we use a static model holding capital fixed and modeling saving as another element of final demand. With a few exceptions (noted below) we allow capital to be fully malleable among sectors. Along with the fact that our sectoral policy simulations are typically modeled ten years into the future, this has the effect of mixing short-, medium-, and long-term assumptions about capital: aggregate capital is fixed, the sectoral results used to calibrate elasticities and non-price policies allow moderate capital turnover, and capital can shift costlessly among sectors. We believe that this combination represents a reasonable trade-off between simplicity and policy relevance, allowing us to get at our interest in the interactions among policies without the overhead of a complex dynamic CGE model. ${ }^{23}$

22. While we estimated reduced-form elasticities for commercial building energy demand, we did not consider policies in that sector.

23. Expanding the model to represent multiple periods would be an interesting area for further work. 
Labor supply is endogenous; we use an elasticity of 1.7 between leisure and other goods. ${ }^{24}$ Real government spending is held fixed across simulations, with government revenue coming from indirect business taxes (modeled as output taxes), income tax on labor and capital, and any revenue from carbon pricing. In this way, our simulation of carbon price policies is best thought of as either a carbon tax or auctioned permit system, with all revenue being recycled into cuts in the income tax.

We assume elastic exports (elasticity of 10) and relatively inelastic imports (elasticity of 0.465 ). Imports are elastically substitutable with domestic goods in the production of a composite domestic-import good according to a standard Armington model with elasticities of 3.0. All of these trade elasticities are based on Ballard et al. (1985). The foreign exchange rate adjusts to maintain a fixed level of real foreign saving.

We use estimates of elasticities of substitution among fuels and among capital, labor, energy, and materials from McKibbin et al. (1999) for those sectors where we do not work with detailed sectoral models (coal, oil, gas, and commercial transportation). ${ }^{25}$ For coal and natural gas production, we deviate from our assumption of fully malleable capital and assume fixed, sector-specific stocks. This allows us to better match expected supply response suggested by the detailed model of the electricity sector, which includes natural gas and coal supply models. We also use a lower KLEM elasticity for coal (0.334) than McKibbin et al. to better match the coal supply results from the detailed electricity sector model.

We use a tiered structure for household consumption (see Figure 4) that incorporates the elasticities for leisure and household transportation, noted earlier, as well as residential energy use. ${ }^{26}$ We use an elasticity of 0.25 between energy and other goods based on an average of previous studies (Dahl 1993) while our elasticity of 0.05 among fuels was informed by historical data. ${ }^{27}$ Domestic savings is combined with household consumption to define household utility (with unit elasticity). Final demand for investment and government goods are modeled as Cobb-Douglas. Demand for both is fixed in real terms with income taxes adjusting endogenously to meet the government budget constraint.

24. This is based on an uncompensated labor supply elasticity of 0.2 (Fuchs et al. 1998) and a compensated elasticity of 0.35 (Blundell and McCurdy 1999).

25. Generally, a KLEM elasticity of 0.5 an energy elasticity of 0.2 . Gas has a KLEM elasticity of 0.8 and an energy elasticity of 0.9 .

26. Our tiered structure follows most existing models, assuming that leisure is an average substitute for consumption of other goods. This implies that rising energy prices will shift consumption towards leisure, reduce the labor supply, and exacerbate tax distortions in the labor market (for example, see Goulder et al. 1999) Recent work suggests that energy products, particularly gasoline, may be a leisure complement and reverse this effect (Williams and West 2004).

27. Absent estimates in the existing literature for the elasticity among fuels, we fit our nested model to historic time series data on energy use and prices from 1983-2000. The model estimated an elasticity of $0.10(0.08)$ between energy and other goods and $0.01(0.05)$ among fuels (standard errors in parentheses). Because the existing literature suggested a higher value for the energy-other good elasticity than we estimated, though still within a 95\% confidence interval, we used a slightly higher value $(0.05)$ for the elasticity among fuels. 
Figure 4. Structure of Household Demand

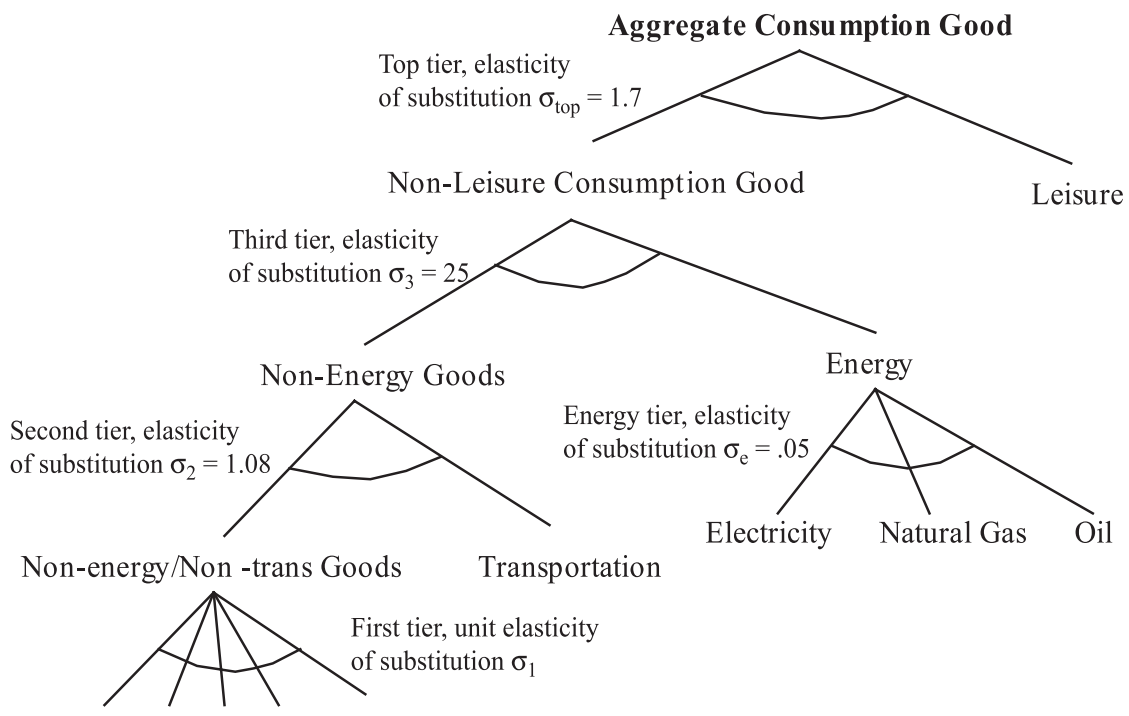

Non-energy/Non -transportation Goods

Equilibrium in the model is defined by supply meeting demand for all goods, zero profit in all sectors, and a binding income constraint for households. Additional details about the model, including programming code, are available from the authors (see Pizer et al. 2003).

\section{GENERAL EQUILIBRIUM RESULTS}

The advantage of a general equilibrium model is that it allows us to compute a broader concept of policy cost that includes effects in other markets. A GE model also accounts for what happens when all market equilibrate, which may be different from partial equilibrium assumptions that necessarily hold certain features constant. With the completed model in hand, we can now take advantage of this capacity to evaluate a menu of policy options as well as compare partial to general equilibrium results.

\subsection{Comparison of Policies to Reduce Carbon Emissions}

Most economic studies of climate change policy focus on the cost of reducing emissions through an economy-wide carbon pricing policy (an emission tax or cap and trade program). We also consider three alternate policies: (1) a more limited economy-wide carbon pricing policy that excludes residential, commercial buildings, investment, and government emissions; (2) a trading program 
that only includes electricity and household transportation (and thus excludes industry, commercial transport and primary fuel extraction); and (3) a combination of non-carbon-price policies, that is, CAFE standards in the household transportation sector and an RPS in the electricity sector. In the carbon pricing policies, we assume all revenue goes to the government and is used to cut income taxes. This places the market-based policies in the best possible light, and sets us up to measure the largest possible discrepancy with non-price policies. ${ }^{28}$ For the non-price policies, we assume proportional reductions in both household transportation and electricity enforced by CAFE and an RPS.

While the economywide carbon pricing policy would need to be implemented upstream in order to capture the myriad small sources, the other two carbon pricing policies are designed to consider the likely implementation of a mostly downstream trading program with transportation handled upstream (e.g., the architecture suggested by S.139, the McCain-Lieberman Climate Steward Act). Downstream programs are limited to large sources and would inevitably exclude households and many commercial / government buildings. At the same time, transportation is about $30 \%$ of total emissions and would need to be covered in any meaningful program. Household transportation emissions are about twothirds of total transportation.

The non-price policy focuses on possibilities suggested by recent events. First, more than seventeen states have enacted requirements that a certain share of their electricity generation be supplied by renewable sources (Union of Concerned Scientists 2004), the U.S. Senate has twice passed legislation to establish a federal RPS, and the 2005 Energy Policy Act included a provision to establish a national RPS up until the final conference version. Second, we have seen both federal and state efforts to improve fuel economy (Pickler 2002; Booth 2002). While proposals exist for more comprehensive legislation, they are unlikely to progress very far in the near term (Pianin 2003). With this in mind, we consider a policy where an RPS is implemented at the national level alongside increased fuel economy standards. In particular, we consider a policy that imposes uniform reductions in both the household transportation and electricity sectors in order to compare aggregate impacts with the other three policies.

Figure 5 shows the marginal welfare cost (\$/ton carbon) for the four alternate policies and a range of emission reductions from 0 to $10 \%$ of total emissions; Table 3 summarizes permit prices and GDP costs for a fixed reduction of $5 \%$. Our economy-wide policy suggests that a $5 \%$ reduction can be obtained with a \$19 per ton carbon price. Before comparing alternative market and non-market sectoral policy results, it is useful to first note that this economywide result falls squarely in the middle of the estimates reported by Weyant and Hill (see Figure

28. We set the exercise up in this way to highlight costs relative to the most cost-effective solution. Assuming auction revenue is returned to households in a lump-sum fashion (or alternatively, that permits are grandfathered) would raise the cost of the market-based policies (Goulder et al. 1999) Examining this question of handling permit revenues has been discussed extensively in the "double dividend" literature and is not the goal of our analysis. 
10(a) 1999). This suggests our aggregate results are broadly consistent with previous work.

Comparing policies, the economywide and industry-transportation-electricity carbon pricing policies have nearly identical welfare costs. A simple message from these results is that it does not substantially raise costs to exclude commercial buildings, households, government, and investment from a market-based policy. Figure 6 indicates together these sources constitute up to a fifth of emissions.

Focusing just on electricity and transportation, which are responsible for just under 50 percent of emissions, doubles cost relative to the economy wide policy. What truly drives up costs is the use of substantially less efficient RPS and CAFE style policies, which have roughly ten times the cost. While the simple message may be that RPS and CAFE are particularly inefficient, there are number of more subtle messages that also emerge from the results as well as explain the simple message. First, Table 3 reveals that while dropping several sectors of the economy from an otherwise economywide program raises the carbon price by $40 \%$ (from $\$ 19$ to $\$ 27$ per ton), welfare costs rise only very slightly (from $\$ 22$ to $\$ 24$ per ton, remaining at about $0.016 \%$ of GDP). This relates back to the early observation that in an economy with existing distortions, producer prices are not always appropriate for valuing public goods. Here, the culprit is indirect business taxes (IBT) (e.g., property, excise, and other indirect business taxes) in the commercial building sector- $7.3 \%$ compared to $1.3 \%$ in industry and $6.4 \%$ in electricity ${ }^{29}$ Including commercial buildings in a trading program may expand the opportunities to reduce emissions (thereby lowering the permit price), but equating the market price of carbon across sectors leads to welfare losses because of the particularly adverse interaction with the IBT in the commercial building sector (e.g., see Goulder 1995; Parry 1997). This is exacerbated by disproportionate reductions in this sector: as Figure 7 indicates, a 5\% economywide emission reduction leads to $8 \%$ reductions in the commercial building sector.

\section{Table 3. Simulation Results for 5\% Aggregate Reductions Through Alternate Policies}

\begin{tabular}{|c|c|c|c|c|c|}
\hline Policy & $\begin{array}{c}\text { Cost } \\
(\% \text { GDP })\end{array}$ & $\begin{array}{c}\text { Permit } \\
\text { price } \\
\text { (\$/ton } \\
\text { of carbon) }\end{array}$ & $\begin{array}{c}\text { Marginal } \\
\text { Welfare } \\
\text { Cost } \\
\text { (\$/ton } \\
\text { of carbon) }\end{array}$ & $\begin{array}{l}\text { Real Wage } \\
\text { (\% change) }\end{array}$ & $\begin{array}{c}\text { Foreign } \\
\text { Exchange } \\
\text { (\% change) }\end{array}$ \\
\hline Carbon price; economy-wide & $0.016 \%$ & $\$ 19$ & $\$ 22$ & $0.014 \%$ & $-0.11 \%$ \\
\hline $\begin{array}{l}\text { Carbon price; industry, transport } \\
\text { and electricity }\end{array}$ & $0.016 \%$ & $\$ 27$ & $\$ 24$ & $0.018 \%$ & $-0.06 \%$ \\
\hline $\begin{array}{l}\text { Carbon price; transport, } \\
\text { electricity sectors only } \\
\text { Renewable electricity portfolio }\end{array}$ & $0.038 \%$ & $\$ 53$ & $\$ 52$ & $-0.009 \%$ & $-0.37 \%$ \\
\hline \& CAFE standards & $0.19 \%$ & $\mathrm{n} / \mathrm{a}$ & $\$ 277$ & $-0.49 \%$ & $-0.10 \%$ \\
\hline
\end{tabular}

29. Note that our model, like most CGE models, treats indirect business taxes as taxes on output. 
Figure 5. Cost of Alternative Policies to Reduce Carbon Dioxide Emissions

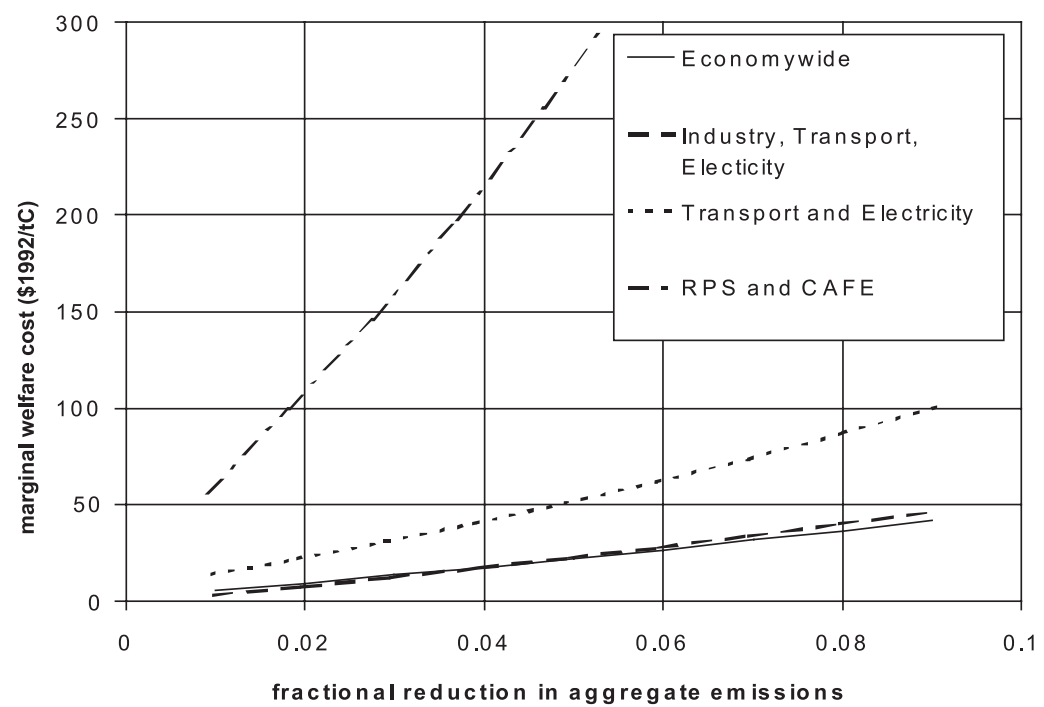

Figure 6. Emission Shares in Reference Case

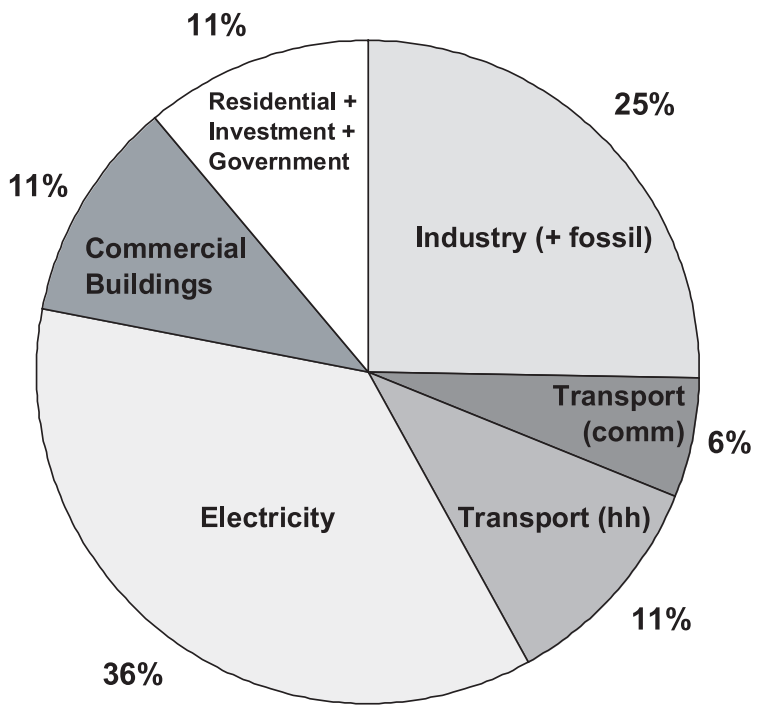


Figure 7. Sectoral Reductions Associated with 5\% Economywide Policy

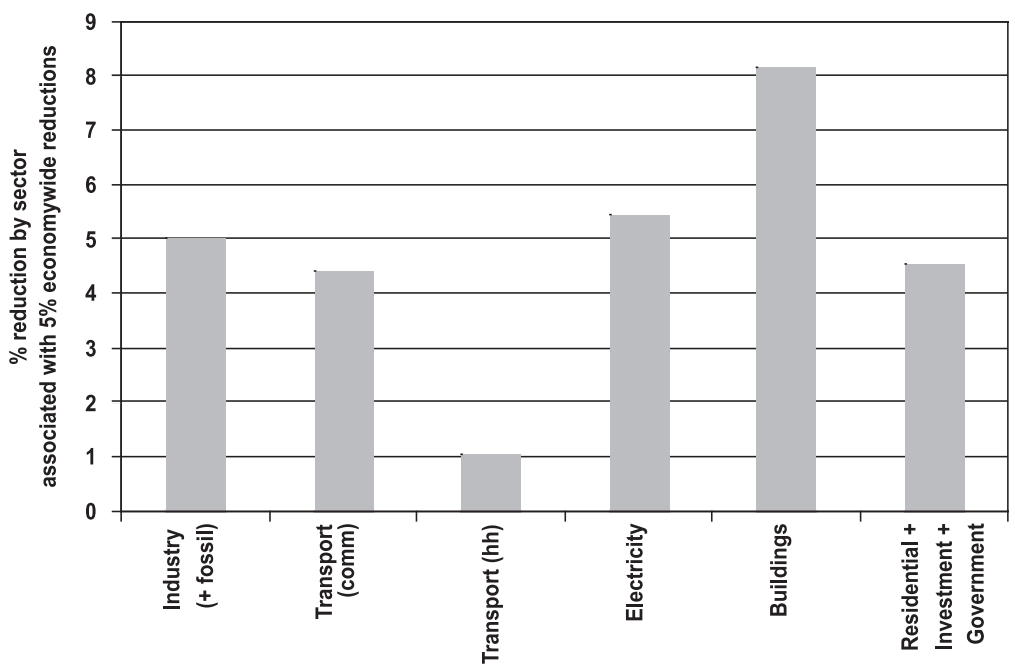

The effect of removing industry stands in contrast to the effect of removing commercial buildings (along with households, investment, and government). Whereas commercial buildings represent a relatively distorted sector in terms of the IBT, industry is relatively undistorted. While removing commercial buildings from the carbon pricing policy maintains roughly the same aggregate costs, further removing industry doubles costs.

Second, the RPS is particularly expensive as a $\mathrm{CO}_{2}$ mitigation policy because it leads to a relative shift from gas to coal as overall fossil generation declines. As noted in the earlier discussion on the electricity sector, this arises from institutional features in the electricity market that place some types of gas generators more at the margin relative to coal, and because an RPS does nothing to penalize coal relative to gas. In the absence of a policy, gas is almost always the marginal fuel so new renewable technologies under the RPS displace gas, which has a lower emission rate than coal. ${ }^{30}$ The failure to emphasize reductions in coal use make an RPS a very inefficient tool for reducing carbon emissions; it is actu-

30. The relative cost of generation per MWh varies significantly within fuel type as well as capacity factor in the solved model. The assumed construction cost in the baseline in 2010 for new coal is $\$ 1,468$ per $\mathrm{kW}$, for new combined cycle it is $\$ 680$, for new gas turbine it is $\$ 341$ and for new wind it is $\$ 1,313$. Considering the expected capacity factor (indicated in parenthesis) were these technologies chosen and built by the model, the long-run marginal cost of new coal generation is $\$ 43 / \mathrm{MWh}(82 \%)$, and for new natural gas combined cycle it is $\$ 46 / \mathrm{MWh}(54 \%)$. In contrast new wind has a long-run marginal cost of about \$75/MWh (31\%) not including the renewable energy production tax credit. However, in the long-run gas is usually the fuel for incremental investment in generation because of greater flexibility in scheduling operation than coal. 
ally hard to push an RPS to achieve more than $20 \%$ reductions in $\mathrm{CO}_{2}$ because of this failure. ${ }^{31}$

Third, CAFE is expensive for an entirely different reason related to our modeling of taxes on capital. In our model, factor inputs of labor and capital are taxed at a rate of about $15 \%$. However, we do not tax the use of capital to provide household transportation. Much like owner-occupied housing (which is not addressed in our model), the implied return from owner-driven vehicles flows directly to consumers without any tax on the capital return. This leads to a distortion among capital uses, with a relatively high amount of household vehicles and relatively low amount of all other, taxed capital (which must have a $15 \%$ higher pre-tax return to balance its after-tax return with untaxed returns to household vehicles). ${ }^{32}$

CAFE requirements further exacerbate this distortion between vehicle and other types of capital by drawing in more vehicle capital to produce more fuel-efficient household transportation. Indeed, even though CAFE contributes less than a third of the reductions arising under the RPS, it is responsible for about half of the added welfare costs (both policies are set up to achieve the same percentage reductions, but electricity production generates more than three times the emissions associated with household transportation). Under a carbon pricing policy, there is still a relative shift from energy to capital in household transport, but there is a much greater reduction in household transportation services owing to increased costs of production associated with pricing inframarginal emissions. That is, while CAFE shifts household transport towards more capital and less fuel, there is no increased cost (such as a fuel tax or required permit) associated with the gasoline that is still used. A carbon-pricing policy, through greater reductions in overall consumption of household transport, reduces the distortion associated with household transport capital.

The last two columns of Table 3 attempt to provide some additional insight into the welfare effects described so far. The next-to-last column reveals changes in the real wage. Because labor supply is endogenous and subject to a distorting income tax, decreases in the real wage and corresponding declines in labor supply imply real welfare losses. However, the pattern of increases and declines suggest that this effect is not particularly strong: the real wage rises in the economywide policy and falls in the electricity/transportation only policy, yet both see a $\$ 5 /$ ton difference in marginal welfare costs compared to allowance

31. Palmer and Burtraw (2005) find a knee of the curve in the cost-effectiveness of an RPS policy between $15 \%$ and $20 \%$ goals for the year 2020. They find partial equilibrium welfare cost per ton of carbon reduced to be $50 \%$ greater than the cost of a carbon trading policy with emission allowances distributed on an updated share of generation. Elsewhere (Burtraw et al. 2001), this type of policy is shown to be 2 to 3 times less efficient than a policy with permits auctioned and revenues distributed lump sum. The CGE model takes another step that cannot be captured by these detailed partial equilibrium models by accounting for the role of previous distortions away from economic efficiency. The tax policy we model recycles revenues in order to reduce pre-existing taxes.

32. Note that we do not model any market imperfections due to consumer undervaluation of future energy savings, which would tend to imply underinvestment in energy efficiency and at least partially offset the above effect. 
prices (e.g., marginal "market" costs). ${ }^{33}$ Similarly, the price of foreign exchange shown in the last column captures part of a potential transfer to foreigners in a model with fixed real foreign savings, such as ours. With the price of foreign exchange falling foreigners are worse off, in turn generating a welfare gain for the United States. Yet, these declines again bear no relation to the discrepancy between allowance price and marginal welfare costs - the larger foreign change declines are associated with the cases where marginal welfare costs are higher than allowance prices, exactly the opposite that theory would suggest. Looking at these two variables, therefore, supports our earlier focus on capital distortions and the indirect business tax.

Summarizing, our simulations show minimal consequences associated with excluding a few relatively small sectors from an otherwise economy-wide cap-and-trade program. This is particularly true for sectors with relatively high taxation. Costs double when the cap-and-trade is limited to power plants and household transportation, partly because of the significant reduction in access to mitigation options but also because of the relatively low existing distortions in industrial production that make them a particularly appealing sector to include. Costs go up by a factor of ten when, instead of market-based carbon pricing, we apply an RPS and CAFE to the electricity and transportation sectors. Here, the story is about both the inefficiency of policies that do not directly target emissions as well as pre-existing taxes and their capacity to dramatically alter the costs of a program.

\subsection{Comparison of Partial and General Equilibrium Results}

It is useful to recap the performance of general versus partial equilibrium analyses. This paper was motivated by the fact that general equilibrium analysis provides full cost estimates that are unavailable in a partial equilibrium analysis. Previous studies have found that partial equilibrium analyses, even with extensions to other markets, do poorly at capturing real welfare costs (Kokoski and Smith 1987). This paper is no different. However, partial equilibrium analysis does do a reasonable job of predicting emission responses. Consider the panels in Figure 8. For the four sectors where we calibrated production elasticities, we show the reduction supplied (horizontal axis) at different carbon prices (vertical axis). We show these schedules based on both a simple partial equilibrium analysis that holds input prices and output level constant (solid lines), and for our general equilibrium analysis where all markets equilibrate (dash-dot). Note that both schedules are based on the fitted reduced-form model, unlike Figure 3 where we compare detailed and reduced-form models. What we see is that in three out of four cases, the partial equilibrium schedule closely matches the general equilibrium schedule. That is, a partial equilibrium analysis does a good job of predicting emission response to a particular carbon price in that sector as forecast by the general equilibrium model. The one exception is electricity, where reductions in output are responsible for an

33. The difference between these two measures summarizes the effect of distortions in the economy. Absent any distortions, these measures would be equal. 


\section{Figure 8. General and Partial Equilibrium Abatement Schedules and Welfare Cost}

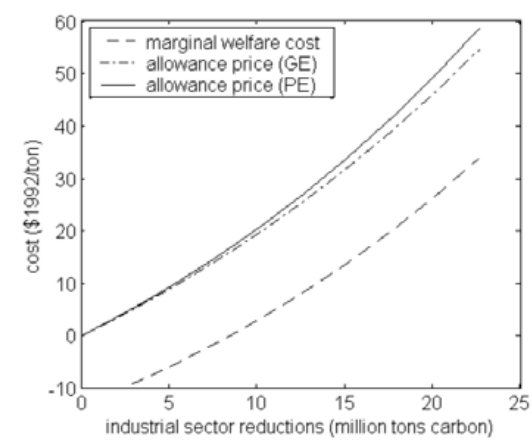

industrial sector

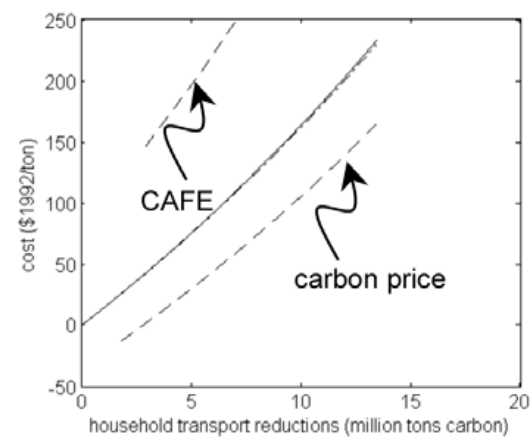

household transportation

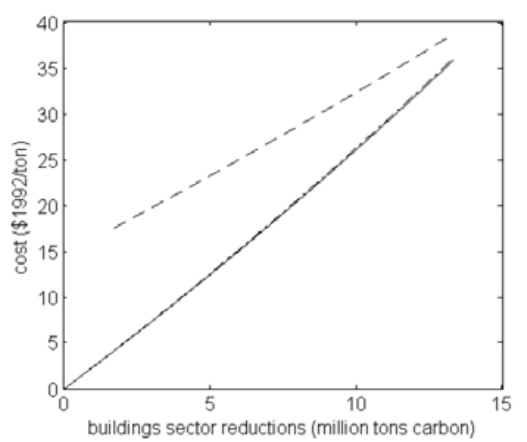

commercial buildings

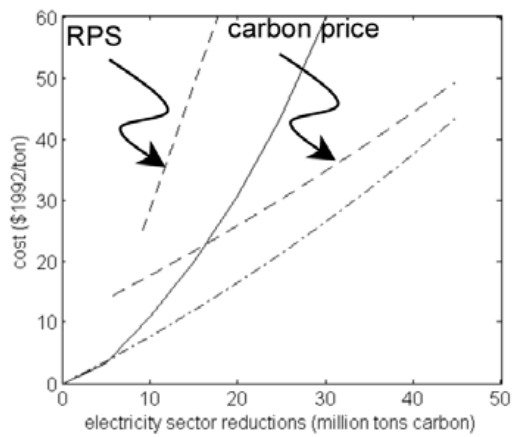

electricity

increasing share of emission reductions as prices rise. Holding output constant in the reduced form partial-equilibrium analysis misses those opportunities, leaving the partial equilibrium schedule to the left of the general equilibrium schedule. ${ }^{34}$

While partial equilibrium analysis effectively captures the emission response as well as the immediate policy costs in that sector, it does a poor job of measuring the impact on consumers and overall welfare. The third line (dashed) in each of the panels in Figure 8 shows the marginal welfare cost of the reductions under carbon price policies-that is the marginal equivalent variation in household income associated with each ton of reductions in a particular sector. There

34. Note that the Haiku model includes demand response and calculates welfare measures within the electricity sector for exactly these reasons. 
we see that while welfare costs are about $\$ 10-15$ per ton of carbon higher than costs measured by the permit price in the buildings and electricity sectors, they are about $\$ 10$ per ton lower in the industry sector and $\$ 50$ per ton lower in household transportation under carbon price policies.

As noted earlier, these distinctions arise because of the pattern of preexisting taxes. Indirect business taxes (IBT) explain the differential pattern between commercial buildings and electricity, which have relatively high IBT, and industry, which has relatively low IBT. The income tax on capital, which is not applied to household transportation capital (in the same way it does not apply to owner-occupied housing), explains the dramatic effect on transportation capital. In theory, knowing the source of the distortions driving these distinctions would allow an extended-market analysis - but often it will be as hard to know these sources as to build a general equilibrium model. ${ }^{35}$ The panels also show the even higher general equilibrium welfare costs of the CAFE and RPS policies.

Before concluding, a word of caution is in order: These additional costs or benefits attributed to pre-existing distortions require that these distortions be modeled carefully. For example, our model of taxes is stylized-we do not attempt to replicate the complexity of the U.S. tax system. We have ignored nonlinearities in the income tax, payments to social security, and the double taxation of corporate profits. Most general equilibrium models are not designed to capture the plethora of existing tax rules. ${ }^{36}$ Nor are many economists likely to agree on the assumptions necessary to pin down the distortions. For instance, policies that exclude household capital (homes and automobiles) from taxation lead to distortions in the allocation of capital among sectors but also may contribute to community stability and/or progressivity in the tax system. There is also a question of whether one wants to use environmental policy to undo tax policy when this might be undone by actual tax reform. These concerns suggest that while general equilibrium exercises are a useful source of qualitative information and gross quantitative information, one should recognize that they inject a large number of additional assumptions into analysis that might otherwise be well-served by a partial equilibrium analysis more fully grounded in institutional details.

\section{CONCLUSIONS}

Existing studies of climate change policy costs have tended to focus on efficient, economy-wide cap-and-trade or carbon tax approaches. In reality, a more limited cap-and-trade or even a disconnected set of non-market policies is more likely to arise in public policy. To study such approaches requires a general equilibrium model that can mimic non-carbon-price policies in particular sectors; otherwise, important interactions among policies are likely to be overlooked.

This paper presented a model that uses detailed sectoral models to calibrate behavior in simpler, reduced-form specifications that are combined in a

35. See discussion in Kopp and Pizer (forthcoming).

36. Studies that explicitly consider tax reform are an exception; see Jorgenson and Yun (1991). 
CGE framework. The calibration involved finding elasticities to match market response and sets of price distortions and productivity shocks to represent nonmarket policies. The result is a CGE model capable of considering renewable portfolio standards in the electricity market, fuel economy standards for cars and light trucks, and uniform performance standards for industry.

The model was applied to four polices: (1) an economy-wide carbon pricing policy, (2) a carbon pricing policy that excludes residential, commercial building, investment, and government emissions, (3) a carbon pricing policy for electricity and transportation only, and (4) combination of an RPS in the electricity sector and CAFE standards for automobiles. Compared to the economy-wide policy, we found that the exclusion of residential, commercial building, investment, and government emissions made virtually no difference in the schedule of marginal welfare costs of the carbon policy over reduction levels ranging up to ten percent. Accounting for only $20 \%$ of emissions and having either inelastic emissions (residential) or high costs due to pre-existing distortions (commercial), costs were almost unchanged or even slightly lower (at reduction levels below $4 \%$ ) when these sources of emissions were excluded from the program. However, limiting the program to only electricity generation and transportation more than doubled costs in our analysis. In this case, significant reduction opportunities were given up in the industrial sector.

At an aggregate reduction of five percent we find that costs are more than 10 times higher when fuel economy standards and a renewable portfolio standard for power plants are imposed with both sectors facing equal percentage reductions. Each policy contributes roughly half of the noted increase in costs, even though fuel economy standards achieve about one-third as many reductions. In the case of an RPS for electricity, the policy fails to distinguish between coal and gas despite the roughly double emissions from coal per million Btu. In the case of fuel economy standards for light-duty vehicles, there is a significant pre-existing distortion among capital uses owing to the absence of taxes on household capital services (e.g., cars and owner-occupied housing). This distortion means relatively more investment in cars and relatively less investment in other, taxed, uses from the perspective of economic efficiency. Unlike carbon pricing policies (taxes and permits), fuel economy standards dictate more capital-intensive transport without increasing the price of gasoline and depressing overall driving; the net effect is an increase in vehicle capital that worsens the pre-existing distortion.

Despite these dramatic and intuitive results, we would caution leaning too much on the quantitative analysis. The representation of taxes in the model is necessarily crude and the cost of distortions in other markets is only as accurate as the parameterization in those markets. While detailed models based on empirical data have been used in the partial equilibrium analysis, other parts of the model have been parameterized from literature surveys and other sources. Finally, the comparison we make is between an emissions tax with revenue recycled in an efficient manner to sector policies. We do not compare the sector policies to a less efficient emissions tax or trading program in which revenues are not recycled 
efficiently, for example, if permits are grandfathered to incumbent emitters, as characterizes most existing emissions trading programs.

Even with these caveats, we demonstrate the capability to compare a variety of non-carbon-price sector-specific policies that may be components of actual public policy and evaluate the relative efficiency cost compared to leastcost strategies. The result that policies like an RPS and CAFE turn out to be considerably more expensive than broad-based market alternatives should be a signal to decision makers who favor narrower, non-price policies. Policy makers may be unaware of the relative cost of these policies, or it may be that other concerns trump economic efficiency. In either case, the information we develop about relative cost-effectiveness can benefit the shaping of public policy.

\section{REFERENCES}

State of California, Air Resources Board (2004). Public Hearing to Consider Adoption of Regulations to Control Greenhouse Gas Emissions from Motor Vehicles. September 23.

Ballard, Charles L., Don Fullerton, John B. Shoven, and John Whalley (1985). A General Equilibrium Model for Tax Policy Evaluation. Chicago: University of Chicago Press.

Bast, Joseph L., James M. Taylor, and Jay Lehr (2003). State Greenhouse Gas Programs: An Economic and Scientific Analysis. Chicago: Heartland Institute.

Berkovec, James (1985). "New Car Sales and Used Car Stocks: A Model of the Automobile Market." Rand Journal of Economics 16 (2):195-214.

Blundell, Richard W., and Thomas McCurdy (1999). "Labor Supply: A Review of Alternative Approaches." In Handbook of Labor Economics, edited by O. Ashenfelter and D. Card. Amsterdam: North-Holland.

Böhringer, Christoph (1998). "The synthesis of bottom-up and top-down in energy policy modeling." Energy Economics 20 (2):233-248.

Böhringer, Christoph, and Thomas F. Rutherford (2005). "Integrating bottom-up into top-down: A mixed complementarity approach." Mannheim: Centre for European Economic Research.

Booth, William (2002). "Calif. Takes Lead on Auto Emissions: Gov. Davis to Sign Law On Pollution That May Affect All U.S. Drivers.” Washington Post, July 22, A1.

Boyd, James, Dallas Burtraw, Alan Krupnick, Virginia McConnell, Richard G. Newell, Karen Palmer, James N. Sanchirico, and Margaret Walls (2003). "Trading Cases: Is Trading Credits in Created Markets a Better Way to Reduce Pollution and Protect Natural Resources?" Environmental Science and Technology 37 (11):216-223.

Bureau of Economic Analysis (2002). "A Guide to the NIPAs." Washington: Bureau of Economic Analysis.

Burtraw, Dallas, Ranjit Bharvirkar, and Meghan McGuinness (2003). "Uncertainty and the Net Benefits of NOx Emission Reductions from Electricity Generation.” Land Economics 79 (3).

Burtraw, Dallas, Alan Krupnick, Karen Palmer, Anthony Paul, Mike Toman, and Cary Bloyd (2003). "Ancillary Benefits of Reduced Air Pollution in the United States from Moderate Greenhouse Gas Mitigation Policies in the Electricity Sector." Journal of Environmental Economics and Management.

Burtraw, Dallas, Karen Palmer, Ranjit Bharvirkar, and Anthony Paul (2001). The Effect of Allowance Distribution on the Cost of Carbon Emission Trading. Washington, DC: Resources for the Future.

Dahl, Carol (1993). "A Survey of Energy Demand Elasticities in Support of the Development of the NEMS.” Washington: Energy Information Administration.

Diamond, Peter A., and James A. Mirrlees (1971). "Optimal Taxation and Public Production II: Tax Rules." The American Economic Review 61 (3):261-278.

Dubin, Jeffrey, and Daniel McFadden (1984). "An Econometric Analysis of Residential Electric Appliance Holdings and Consumption.” Econometrica 52 (2):53-76. 
EIA. (1998). "Impacts of the Kyoto Protocol on U.S. Energy Markets and Economic Activity." Washington: Energy Information Administration.

(1999). "Model Documentation Report: Industrial Sector Demand Module of the National Energy Modeling System.” Washington, DC: EIA.

(2000). "Analysis of Strategies for Reducing Multiple Emissions from Power Plants: Sulfur Dioxide, Nitrogen Oxides, and Carbon Dioxide." Washington, DC: EIA.

— (2001). Annual Energy Outlook 2002. Washington, DC: U.S. Energy Information Administration.

(2003). "Analysis of S. 139, the Climate Stewardship Act." Washington: EIA.

Energy Modeling Forum (1998). "A Competitive Electricity Industry." Stanford: Energy Modeling Forum.

(2001).'Prices and Emissions in a Competitive Electricity Sector.” Stanford: Energy Modeling Forum.

Fischer, Carolyn (2001). "Rebating Environmental Policy Revenues: Output-Based Allocations and Tradeable Performance Standards." Washington, DC: Resources for the Future.

Fischer, Carolyn, and Richard Newell (2004). "Environmental and Technology Policies for Climate Change and Renewable Energy." In RFF Discussion Paper 04-05. Washington, DC.

Frei, Christoph W., Pierre-André Haldi, and Gérard Sarlos (2003). "Dynamic formulation of a topdown and bottom-up merging energy policy model." Energy Policy 31:1017-1031.

Fuchs, Victor R., Alan B. Krueger, and James M. Poterba (1998). "Economists' Views about Parameters, Values and Policies: Survey Results in Labor and Public Economics." Journal of Economic Literature 36:1387-1425.

Ghersi, Frederic, and Michael Toman (2003). "Modeling Challenges in Analyzing Greenhouse Gas Trading." Washington: Resources for the Future.

Goldberg, Pinelopi (1998). "The Effects of Corporate Average Fuel Efficiency Standards in the US." Journal of Industrial Economics 46 (1):1-33.

Goulder, Lawrence H. (1995). "Effects of Carbon Taxes in an Economy with Prior Tax Distortions: An Intertemporal General Equilibrium Analysis." Journal of Environmental Economics and Management 29 (3 (Part 1)):271-297.

Goulder, Lawrence, Ian Parry, Roberton Williams, and Dallas Burtraw (1999). "The Cost-Effectiveness of Alternative Instruments for Environmental Protection in a Second-Best Setting." Journal of Public Economics 72:329-360.

Harrington, Winston, James N. Sanchirico, and Margaret Walls (2003). "Effects of Climate Change Policies on the US Household Transportation Sector." Washington, DC: Resources for the Future.

Herman, Shelby W. (2000). "Fixed Assets and Consumer Durable Goods." Survey of Current Business 80 (4): 17-30.

Jaccard, Mark, John Nyboer, Chris Bataille, and Bryn Sadownik (2003). "Modeling the Cost of Climate Policy: Distinguishing Between Alternative Cost Deftitions and Long-Run Cost Dynamics." The Energy Journal 24 (1):24.

Jorgenson, D.W., and K.-Y. Yun (1991). Tax Reform and the Cost of Capital. Oxford: Claredon Press. Kehoe, Patrick J., and Timothy J. Kehoe (1994). "A Primer on Static Applied General Equilibrium Models." Federal Reserve Bank of Minneapolis Quarterly Review 18 (1).

Kleit, Andrew N. (1990). "The Effect of Annual Changes in Auto Fuel Economy Standards." Journal of Regulatory Economics 2:151-172.

Kokoski, Mary F., and V. Kerry Smith (1987). "A General Equilibrium Analysis of Partial-Equilibrium Welfare Measures: The Case of Climate Change." The American Economic Review 77 (3):331-341.

Kopp, Raymond, and William Pizer (forthcoming). "Calculating the Costs of Environmental Regulation." In Handbook of Environmental Economics, edited by K. Goran-Maler and J. Vincent. Amsterdam: Elsevier.

Kwoka, John E. (1983). "The Limits of Market-Oriented Regulatory Techniques: The Case of Automotive Fuel Economy." Quarterly Journal of Economics 98: 695-704.

Lawson, Ann M. (1997). "Benchmark Input-Output Accounts for the United States". Survey of Current Business 77 (11): 36-82. 
McFarland, J. R., J. M. Reilly, and H. J. Herzog (2004). "Representing energy technologies in topdown economic models using bottom-up information." Energy Economics 26 (4): 685-707.

McKibbin, Warwick, Martin Ross, Robert Shackleton, and Peter Wilcoxen (1999). "Emissions Trading, Capital Flows and the Kyoto Protocol.” Washington, DC: Brookings Institution.

National Energy Policy Development Group (2001). National Energy Policy. Washington: GPO.

National Research Council (2002). Effectiveness and Impact of Corporate Fuel Economy (CAFE) Standards. Washington, DC: National Academy Press.

Newell, Richard, and William Pizer (2003). "Commercial Building Energy Demand." Washington: Resources for the Future.

Newell, Richard, James Sanchirico, and Suzi Kerr (2005). "Fishing Quota Markets.” Journal of Environmental Economics and Management 49 (3):437-462.

Palmer, Karen, and Dallas Burtraw (2005)."Cost-Effectiveness of Renewable Electricity Policies." Energy Economics 27(6): 873-894.

Parry, Ian W. H. (1997)."Environmental Taxes and Quotas in the Presence of Distorting Taxes in Factor Markets." Resource and Energy Economics 19 (3):203-20.

Parry, Ian W. H., and Roberton C. Williams (1999). "A Second-Best Evalulation of Eight Policy Instruments to Reduce Carbon Emisssions." Resource and Energy Economics 21:347-373.

Paul, Anthony, and Dallas Burtraw (2002). "The RFF Haiku Electricity Market Model." Washington: Resources for the Future.

Pianin, Eric. (2003). "Fight Ahead on Emissions: McCain, Lieberman Plan Push for Greenhouse Gas Limits." Washington Post, January 7, A4.

Pickler, Nedra (2002). "Higher Fuel Averages Proposed Automakers Say Legislation Endangers SUVs, Light Trucks." Washington Post, February 9, E2.

Pizer, William, Dallas Burtraw, Winston Harrington, Richard Newell, James N. Sanchirico, and Michael Toman (2003). "General and Partial Equilibrium Modeling of Sectoral Policies to Address Climate Change in the United States." Washington, DC: Resources for the Future.

RGGI State Commissioners (2004). Regional Greenhouse Gas Initiative (RGGI): Goals, Proposed Tasks, and Short-Term Action Items 2003. Available from http://www.rggi.org. [cited October 2004].

Stavins, Robert N. (2002). "Lessons from the American Experiment with Market-Based Environmental Policies." In Market-Based Governance: Supply Side, Demand Side, Upside and Downside, edited by J. John D. Donahue and Joseph S. Nye. Washington DC: Brookings Institution.

Thorpe, Steven (1997). "Fuel Economy Standards, New Vehicle Sales, and Average Fuel Efficiency." Journal of Regulatory Economics 11:311-26.

Train, Kenneth (1986). Qualitative Choice Analysis: Theory, Econometrics, and an Application to Automobile Demand. Cambridge, MA: MIT Press.

Union of Concerned Scientists (2004). State Minimum Renewable Electricity Requirements 2004. Available from http://www.ucsusa.org/documents/State_Renewable_Energy_Standards.pdf. [cited October 2004].

US EPA (1998). "Analyzing Electric Power Generation under the CAAA.” Washington: EPA Office of Air and Radiation.

Weyant, John P., and Jennifer Hill (1999). The Costs of the Kyoto Protocol: A Multi-Model Evaluation, Introduction and Overview. The Energy Journal Special Issue.

Williams, Roberton, and Sarah West (2004). "Empirical Estimates for Environmental Policy Making in a Second-Best Setting." Cambridge, MA: NBER. 